\title{
Genome Organization of Pseudomonas stutzeri and Resulting Taxonomic and Evolutionary Considerations
}

\author{
MARGARITA GINARD, ${ }^{1,2 *}$ JORGE LALUCAT,${ }^{1}$ BURKHARD TÜMMLER, ${ }^{2}$ AND UTE RÖMLING ${ }^{2} \dagger$ \\ Laboratori de Microbiologia, Departament de Biologia Ambiental, Universitat de les Illes Balears, and Institut d'Estudis Avançats \\ (CSIC-UIB), 07071 Palma de Mallorca, Spain, ${ }^{1}$ and Klinische Forschergruppe and Abteilung Biophysikalische Chemie, \\ Zentrum Biochemie, OE 4350, Medizinische Hochschule Hannover, D-30623, Hannover, Germany ${ }^{2}$
}

\begin{abstract}
In order to determine the genome variability within Pseudomonas stutzeri, 20 strains representing the seven described genomovars and strain JM300 were analyzed by using various resolution levels of rare cutting enzymes. $X b a I$ and $S p e I$ fingerprints revealed a high degree of heterogeneity of restriction patterns that did not correlate with the division into genomovars. However, a fragment pattern comparison led to the establishment of several groups of clonal variants within genomovars. One circular chromosome ranging in size from 3.75 to 4.64 Mb constitutes the genome of $P$. stutzeri strains. The I-CeuI, PacI, and $S w a I$ low-resolution map of $P$. stutzeri type strain CCUG 11256 shows the locations of 12 genes, including $r$ rn operons and the origin of replication. I-CeuI digests of the 20 strains studied plus the positions of six genes allowed a comparison of the rrn backbone organization within genomovars; the four $r$ rn operons seemed to be at similar locations with respect to the origin of replication, as did the rest of the genes. However, a comparison of I-CeuI cleavage maps of the genomovar reference strains revealed a diverse genome organization in the genomovars relative to $r$ rn operons and gene locations. In most genomovars, rrn operons are not arranged around the origin of replication but are equally distributed on the chromosome. Strain JM300 does not belong to any described genomovar, as determined from the organization of its genome. Large chromosomal rearrangements seem to be responsible for the differences in superordinate genome structure and must have played an important role in $P$. stutzeri diversification and niche colonization. An ancestral chromosome is suggested, and some plausible pathways for the generation of the various genome structures are proposed.
\end{abstract}

Pseudomonas stutzeri is a widely distributed nonfluorescent Pseudomonas species. This organism is easy to distinguish from other pseudomonad species by its ability to use maltose and starch as sole carbon and energy sources and its production of dinitrogen gas from nitrate. Workers have become interested in this species because of its metabolic properties, such as degradation of environmental pollutants $(2,73)$ and high-molecular-weight polyethylene glycols (55). P. stutzeri ZoBell and JM300 have been used as model microorganisms to study denitrification $(17,84)$ and natural transformation $(50)$ processes in detail. The unique amylase produced by $P$. stutzeri has been the subject of biochemical studies because it hydrolyzes starch exoglycolytically but releases $\alpha$-anomeric oligosaccharides (22). A variety of human infections have also been associated with $P$. stutzeri (32).

$P$. stutzeri is a member of the genus Pseudomonas sensu stricto in the gamma subclass of the Proteobacteria. DNA-DNA hybridization studies have defined seven clear-cut genomic groups called genomovars $(68,81)$. However, the $P$. stutzeri genomovars are characterized by a high level of heterogeneity of phenotypic properties $(68,69,72)$, which does not allow the taxa to be split into different species. The phylogenetic relationships of 14 strains representing the seven described genomovars were determined recently by workers who compared $16 \mathrm{~S}$ rRNA sequences, and the results confirmed the genomovar division (4). The 16S rRNA sequence of genomovar 6

* Corresponding author. Mailing address: Laboratori de Microbiologia, Departament de Biologia Ambiental, Universitat de les Illes Balears, and Institut d'Estudis Avançats (CSIC-UIB), Carretera de Valldemossa km 7.5, 07071 Palma de Mallorca, Spain. Phone: (3471) 173335. Fax: (3471) 173184. E-mail: dbarbz0@ps.uib.es.

$\dagger$ Present address: Mikrobiologiskt och Tümorbiologiskt Centrum, Karolinska Institutet, S-17177, Stockholm, Sweden. strains was found to be different enough to rename this genomic group a new species, Pseudomonas balearica.

Information on genome structure is a very important component of any comprehensive description of a microorganism (57), and the potential applications of this information to bacterial systematics have been emphasized recently $(11,57,66)$. Comparative analysis of bacterial chromosomes at the intraand interspecies levels can provide information about genomic diversity, phylogenetic relationships, and chromosome dynamics. Intraspecies map comparisons have been performed with Escherichia coli $(5,58)$, Leptospira interrogans (83), Mycoplasma hominis (39), Mycoplasma mycoides (59), Bacillus cereus (9), Clostridium perfringens (7), Rhodobacter capsulatus (19), Pseudomonas aeruginosa (75), Salmonella enterica $(42,43$, 45, 47), Helicobacter pylori (35), and Lactococcus lactis (41).

I-CeuI is an intron-encoded endonuclease (23) that specifically cuts a 19-bp recognition sequence (53) within the $r r l$ gene of a wide variety of bacteria $(24,33,44,56,63)$. Since the number and locations of rRNA genes which can be considered the backbone of a chromosome are thought to be conserved in the chromosomes of bacterial species (18), I-CeuI digests should be useful for analyzing chromosome structure. So far, comparisons of I-CeuI digests of chromosomes of related species have been used as a tool in comparative studies and to detect DNA rearrangements $(42,44,46,48,80)$.

Our knowledge concerning Pseudomonas genomes is limited to three species, $P$. aeruginosa $(31,64,75)$, Pseudomonas fluorescens (60), and Pseudomonas putida (54). Genome fingerprinting was recently used to estimate the genome sizes of 16 $P$. stutzeri strains (61). However, no restriction map of this organism has been published. In this report we describe the basic genome organization of $P$. stutzeri. An analysis of $X b a I$ and SpeI fingerprints allowed us to characterize bacterial strains on the basis of their unique restriction patterns and to identify several groups of clonal variants among the strains 
TABLE 1. P. stutzeri strains used in this study

\begin{tabular}{|c|c|c|c|}
\hline Strain $^{a}$ & Genomovar & Source & Other designation(s) \\
\hline ATCC 17589 & 1 & Clinical isolate (Copenhagen, Denmark, before 1966) & $222^{b}$ \\
\hline CCUG $11256^{\mathrm{Tc}}$ & 1 & Clinical isolate (Copenhagen, Denmark, before 1966) & ATCC $17588^{\mathrm{T}}, 221^{\mathrm{T} b}$ \\
\hline B1SMN1 . & 1 & Wastewater (Menorca, Spain, 1988) & \\
\hline B2SMN1 & 1 & Wastewater (Menorca, Spain, 1988) & \\
\hline S1MN1 & 1 & Wastewater (Menorca, Spain, 1988) & \\
\hline ATCC $17591^{c}$ & 2 & Clinical isolate (Copenhagen, Denmark, 1956) & $224^{b}$ \\
\hline ATCC 17587 & 2 & Clinical isolate (Copenhagen, Denmark, 1956) & $220^{b}$ \\
\hline ZoBell & 2 & Marine isolate (before 1944) & ATCC 14405 \\
\hline DSM $50227^{c}$ & 3 & Clinical isolate & ATCC 11607 \\
\hline LSMN2 & 3 & Marine isolate (Barcelona, Spain, 1988) & \\
\hline AN10 & 3 & Marine isolate (Barcelona, Spain, 1982) & \\
\hline AN11 & 3 & Marine isolate (Barcelona, Spain, 1982) & \\
\hline ST27MN2 & 3 & Marine isolate (Barcelona, Spain, 1988) & \\
\hline $\mathrm{CH} 88$ & 3 & Water isolate (Mendoza, Argentina, before 1970) & \\
\hline $19 \mathrm{SMN} 4^{c}$ & 4 & Marine isolate (Barcelona, Spain, 1988) & DSM 6084 \\
\hline ST27MN3 & 4 & Marine isolate (Barcelona, Spain, 1988) & \\
\hline DNSP21 ${ }^{c}$ & 5 & Wastewater (Mallorca, Spain, 1988) & DSM 6082 \\
\hline $\mathrm{SP} 1402^{\mathrm{T} c}$ & $6^{d}$ & Wastewater (Mallorca, Spain, 1988) & DSM 6083 \\
\hline LS401 & $6^{d}$ & Marine isolate (Barcelona, Spain, 1988) & \\
\hline DSM $50238^{c}$ & 7 & Soil isolate (Berkeley, Calif., before 1966) & ATCC $17832,419^{b}$ \\
\hline JM300 & & Soil isolate (California, before 1982) & \\
\hline
\end{tabular}

${ }^{a}$ Strains were isolated or received under these designations. ATCC, American Type Culture Collection, Rockville, Md.; CCUG, Culture Collection of the University of Göteborg, Göteborg, Sweden; DSM, Deutsche Sammlung von Mikroorganismen und Zellculturen, Braunschweig, Germany.

${ }^{b}$ Strain designation assigned by Stanier et al. (77a).

${ }^{c}$ Genomovar reference strain (68).

${ }^{d}$ Genomovar renamed $P$. balearica sp. nov. (4).

examined. We present I-CeuI physical maps of the genomovar reference strains and a $S w a \mathrm{I}-\mathrm{I}-\mathrm{Ceu} \mathrm{I}-\mathrm{Pac} \mathrm{I}$ low-resolution physical map of the $P$. stutzeri type strain. An I-CeuI cleavage map of $P$. stutzeri JM300 was also constructed. Various genes were located on the maps. Our results and map comparisons led to the following observations: (i) strains belonging to the same genomovar seem to have similar genome architectures; (ii) diverse genome organizations occur in the P. stutzeri genomovars; (iii) the rRNA genes are not concentrated around the origin of replication in most genomovars; (iv) strain JM300 does not belong to any described genomovar, as determined from its genome organization; (v) there is a correlation between taxonomic and phylogenetic data and genome structures; and (vi) DNA rearrangements may have played an important role in the diversification and evolution of $P$. stutzeri.

\section{MATERIALS AND METHODS}

Bacterial strains. A total of 20 strains representing the seven described genomovars $(68,71)$ were used in this study (Table 1). Genomovars 4 through 7 were established with less than three strains. In the case of genomovars 1 through 3 , three to six strains were chosen by considering time, source, and geographical area of isolation. P. stutzeri JM300 (8), which was not included in any of our previous taxonomic studies, was also used in this study in order to validate our conclusions.

Plasmid detection in $\boldsymbol{P}$. stutzeri. Plasmids were detected by the alkaline lysis procedure (74), the Eckhardt method (16), and pulsed-field gel electrophoresis (PFGE) of undigested DNA plugs. Agarose gels (0.8 and $0.6 \%$ agarose) were used for conventional electrophoresis. The Eckhardt method was applied to both conventional and PFGE gels.

Preparation of high-molecular-weight DNA. Bacterial strains were grown overnight at $30^{\circ} \mathrm{C}$ in Luria broth. After centrifugation, cells were resuspended at a concentration of $4 \times 10^{9}$ cells per ml. The method used to prepare DNA has been described previously (67).

Digestion of DNA in agarose blocks. Prior to digestion, agarose plugs were equilibrated three times with restriction buffer. Single digestions were performed as described previously (67) for $S p e \mathrm{I}, X b a \mathrm{I}$, and $\mathrm{PacI}$. To improve the efficiency of I-CeuI digestion, one-half of a plug was digested for $3 \mathrm{~h}$ at $37^{\circ} \mathrm{C}$ with $3 \mathrm{U}$ of enzyme in a $65-\mu \mathrm{l}$ reaction mixture. SwaI restrictions were done at $25^{\circ} \mathrm{C}$ for only $2.5 \mathrm{~h}$. Double digestions were performed sequentially. I-CeuI partial digests were obtained after digestion with $3 \mathrm{U}$ of enzyme for $40 \mathrm{~min}$. I-CeuI-, PacI-, and SwaI-digested blocks were treated with $1 \mathrm{ml}$ of ES $(0.5 \mathrm{M}$ EDTA, $1 \%$ [wt/vol]
$N$-lauroylsarcosine, $0.5 \mathrm{mg}$ of proteinase $\mathrm{K}$ per $\mathrm{ml}[\mathrm{pH} 9.5]$ ) at $56^{\circ} \mathrm{C}$ for $45 \mathrm{~min}$ and then equilibrated with $1 \mathrm{ml}$ of TE buffer $(10 \mathrm{mM}$ Tris, $10 \mathrm{mM}$ EDTA [pH 7.4]). $X b a \mathrm{I}$ and $S p e \mathrm{I}$ digestions were stopped by adding $1 \mathrm{ml}$ of TE buffer at $4^{\circ} \mathrm{C}$. DNA end labelling was carried out as described previously (67). Restriction endonucleases were purchased from New England Biolabs (I-CeuI, XbaI, SpeI, and $P a C I$ ) and Boehringer Mannheim (SwaI).

Fragment nomenclature. DNA fragments produced by single restriction endonuclease digestion were designated $\mathrm{Pa}(\mathrm{PacI}), \mathrm{Sw}(\mathrm{SwaI})$, and $\mathrm{Ce}$ (I-CeuI) to identify the enzyme, followed by capital letters (A, B, C, etc.) in order of decreasing fragment size. Fragments produced by double digestion were assigned numbers $(1,2,3$, etc.) in the same way.

PFGE. PFGE was performed in a contour-clamped homogeneous electric field (CHEF) model DRII and DRIII apparatus (Bio-Rad), in a Gene Navigator apparatus (Pharmacia LKB), or in a purpose-built crossed-field gel electrophoresis unit (77); 0.25× TBE buffer was used for the crossed-field gel electrophoresis apparatus, and $0.5 \times$ TBE buffer was used for the other apparatuses. Agarose concentrations and running conditions were varied in order to obtain optimal resolution of the different molecular weight ranges. BstEII-digested lambda DNA, lambda oligomers, Saccharomyces cerevisiae X2180-1B, Candida albicans LBS562, and Schizosaccharomyces pombe DSM 70576 were used as size standards. Two-dimensional gels were prepared by methods reported earlier (65).

Plasmids and gene probes. The origins of the $c a t A$ (catechol-1,2-dioxygenase), $o p r F$ (outer membrane protein $\mathrm{F}$ ), ace $A B$ (pyruvate dehydrogenase), rec $A$ (RecA protein), and hemL (glutamate-1-semialdehyde-2,1-aminomutase) genes have been described previously $(31,34)$. or (origin of replication) and citA (citrate synthase) probes were obtained by PCR amplification from $P$. aenuginosa as described previously $(15,82)$ and were kindly provided by $C$. Spangenberg. $s s b$ (single-strand binding protein) and hem $B$ (5-aminolevulinate dehydratase) $P$. aeruginosa genes were kindly provided by J. Genschel (23a) and D. Jahn (34a), respectively. The freeze-squeeze method (79) was used to elute the corresponding DNA bands from gels. Nonradioactive labelling of DNA fragments was carried out by random priming by using a Boehringer Mannheim digoxigenin labelling kit. 16S rRNA, 23S rRNA, and nosZ (nitrous oxide reductase) labelled probes were obtained by directly introducing digoxigenin-dUTP during PCR amplification from the $P$. stutzeri type strain (16S rRNA, 23S rRNA) and $P$. stutzeri ZoBell (nos $Z$ ). The $16 \mathrm{~S}$ rRNA and nos $Z$ primers were kindly supplied by A. Bennasar and were designed according to published sequences (GenBank nucleic acid sequence database accession numbers U26262 and M22628, respectively). The $23 \mathrm{~S}$ rRNA primers were selected by using data from reference 51 .

Southern blots and DNA hybridizations. Pulsed-field gels were transferred to a nylon membrane by alkaline capillary blotting for $48 \mathrm{~h}$. Hybridization was carried out as described previously (10) for $48 \mathrm{~h}$. Signals were detected as recommended by the manufacturer (Boehringer Mannheim). 


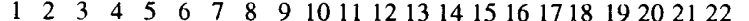

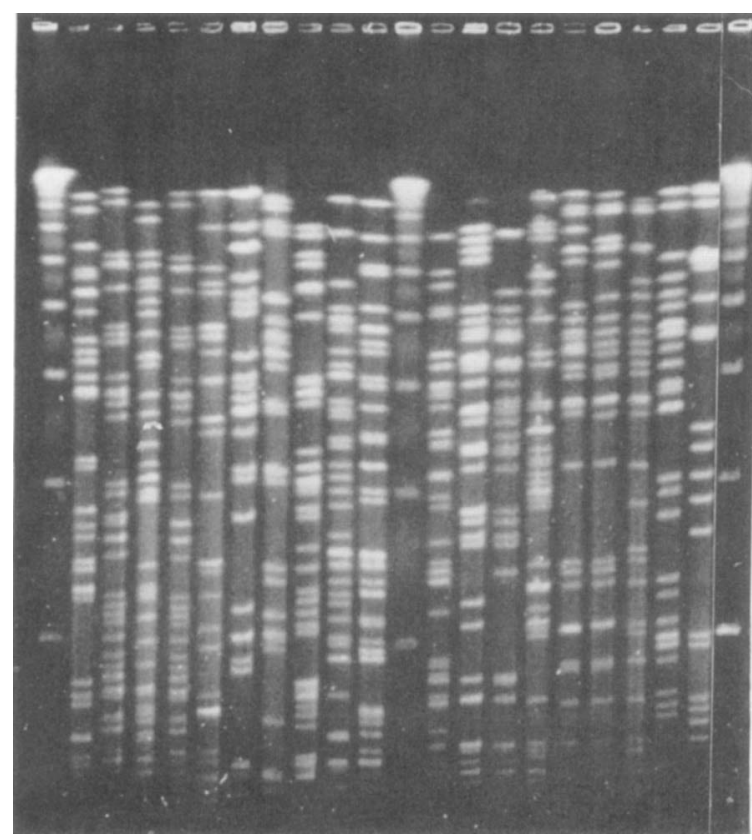

FIG. 1. Macrorestriction fragment patterns of chromosomes of $P$. stutzer strains cut by SpeI. Lanes 1, 12, and 22, ג DNA concatemers; lane 2, DSM 50227; lane 3, ATCC 17587; lane 4, CCUG $11256^{\mathrm{T}}$; lane 5, ATCC 17591; lane 6, ATCC 17589; lane 7, DNSP21; lane 8, DSM 50238; lane 9, ZoBell; lane 10, 19SMN4 lane 11, ST27MN3; lane 13, AN11; lane 14, AN10; lane 15, ST27MN2; lane 16, LSMN2; lane 17, B1SMN1; lane 18, B2SMN1; lane 19, S1 MN1; lane 20, SP1402 lane 21, LS401. The running conditions were as follows: $6.3 \mathrm{~V} / \mathrm{cm}$; reorientation angle, $120^{\circ}$; pulse times linearly increased in two ramps, 1 to $10 \mathrm{~s}$ for $15 \mathrm{~h}$ and 1 to $24 \mathrm{~s}$ for $23 \mathrm{~h}$; agarose concentration, $1 \%$; CHEF model DRIII apparatus.

\section{RESULTS}

Presence of plasmids in $\boldsymbol{P}$. stutzeri. One to four plasmids were detected in 10 of the 21 strains analyzed (strains ATCC 17587, ATCC 17591, ATCC 17589, DNSP21, 19SMN4, ST27MN3, AN11, LSMN2, B1SMN1, and B2SMN2); 72\% of the plasmids observed were smaller than $50 \mathrm{~kb}$, one plasmid was between 50 and $95 \mathrm{~kb}$ long, and four plasmids were larger than $95 \mathrm{~kb}$ (strains 19SMN4, LSMN2, B1SMN1, and B2SMN2). No two strains shared the same plasmid profile. No relationship was found between the genomovars and the distribution of the plasmids among the strains. Interestingly, 7 of the 10 strains that contained plasmids were isolated from polluted environments. A correlation between the degree of contamination and the incidence of plasmids was found in the environmental studies of Baya et al. (3). The Eckhardt method used with both conventional and PFGE gels turned out to be the most reliable and useful method for plasmid detection.

$X b a I$ and SpeI fingerprints and 16S rRNA and 23S rRNA restriction fragment length polymorphisms (RFLPs). $X b a$ I and SpeI restriction enzymes are known to cut the $P$. stutzeri genome into 24 to 42 fragments (61). Consequently, these enzymes were chosen to generate fingerprints in order to explore the $P$. stutzeri genome structure and to determine the degree of relatedness among the strains. The distribution and size range of the fragments generated with these two enzymes, especially SpeI, were optimal for PFGE resolution and for fragment pattern comparisons. The PFGE gels resolved 20 to 34 fragments in the case of the SpeI restriction patterns (Fig. 1) and 36 to 48 fragments in the case of the $X b a \mathrm{I}$ patterns. The similarity and degree of relatedness between macrorestriction patterns were determined as described elsewhere (25). A unique restriction pattern characterized each strain. No correlation between the similarity of macrorestriction patterns and genomovar division was found due to the high discriminatory power of the two enzymes and the heterogeneity of the restriction patterns. A clear distinction between strains on the basis of $\mathrm{G}+\mathrm{C}$ contents, which ranged from 60.9 to $65 \%$ mol\% (68), was also not possible, as predicted by Rainey et al. (61). However, genomovar 2 strains ( $\mathrm{G}+\mathrm{C}$ contents, 60.9 to $62.3 \mathrm{~mol} \%$ $[68,71])$ could be distinguished on the basis of the absence of fragments larger than $175 \mathrm{~kb}$ in $\mathrm{XbaI}$ restriction patterns, as reported previously (61).

Strains ATCC 17591 and ATCC 17587, strains B1SMN1, B2SMN1, and S1MN1, and strains ST27MN2 and AN10 were identified as clonal variants from $\mathrm{XbaI}$ and SpeI fragment pattern comparisons. We believe that the strain 19SMN4-strain ST27MN3 pair is a borderline case that is not easy to define. In all cases, clonal variants were found within a genomovar. The common lineages reflected the origin and date of isolation, and the strains were phenotypically similar $(68,69,72)$; exceptions are strains AN10 and ST27MN2, which were isolated in different years (1982 and 1988, respectively) from marine sediments in Barcelona, Spain.

Two SpeI sites (at positions 449 and 1096), one I-CeuI site (at position 1920), and no $X b a$ I sites were found when the 23S rRNA sequence of $P$. stutzeri ZoBell was checked. Neither $X b a \mathrm{I}$ sites nor SpeI sites were found in the $16 \mathrm{~S}$ rRNA sequence of $P$. stutzeri type strain CCUG 11256 . The $23 \mathrm{~S}$ rRNA probe was designed to lie downstream of the two SpeI sites and the unique I-CeuI site. 23S rRNA and 16S rRNA RFLPs of $X b a \mathrm{I}-$ and SpeI-digested DNA revealed that there are four copies of both genes in the $P$. stutzeri genome. Identical patterns were obtained when $X b a$ I fingerprints were hybridized with both probes, suggesting that the $16 \mathrm{~S}$ rRNA and $23 \mathrm{~S}$ rRNA genes are linked. One exception was found in the case of strain DNSP21 (genomovar 5), where one band smaller than the presumed operon size was detected in $16 \mathrm{~S}$ rRNA RFLPs. In the case of strains belonging to a group of clonal variants, the probes recognized three or four bands with identical molecular weights; nevertheless, only one and two identical bands were recognized in $X b a$ I RFLPs of strains AN10 and ST27MN2 and in $X b a \mathrm{I}$ RFLPs of strains B1SMN1, B2SMN1, and S1MN1, respectively.

Determination of genome parameters: size, number, and topology of the $\boldsymbol{P}$. stutzeri chromosome. Chromosome size was determined by adding the I-CeuI restriction fragment sizes and by calculating the molecular weight of the linearized chromosome. The results are shown in Table 2.

The sizes of the chromosomes of the $P$. stutzeri strains ranged from 3.75 to $4.64 \mathrm{Mb}$. Differences in chromosome size of 70 to $427 \mathrm{~kb}$ were found among strains belonging to the same genomovar, while a maximum difference of $70 \mathrm{~kb}$ was found within clonal variants. The greatest range of variation was found with genomovars 3 and 1 , the genomovars for which the most strains were analyzed. Differences in chromosome size of $0.9 \mathrm{Mb}$ were found when genomovars were compared; however, there was no relationship between chromosome size and genomovars. The largest chromosomes were the chromosomes of genomovar 1 strains B1SMN1, B2SMN1, and S1MN1. The smallest chromosome, $3.75 \mathrm{Mb}$, was found for strain DSM 50238, the single member of genomovar 7. The average chromosome size was $4.29 \mathrm{Mb}$, and the standard deviation was $0.22 \mathrm{Mb}$.

A useful approach for establishing the size, topology, and multiplicity of a genome is separating the linearized chromosome. Plugs of undigested DNAs of all of the strains were 
TABLE 2. Sizes of I-CeuI restriction fragments of $P$. stutzeri strains

\begin{tabular}{|c|c|c|c|c|c|c|}
\hline \multirow{2}{*}{ Strain } & \multirow{2}{*}{ Genomovar } & \multicolumn{4}{|c|}{$\begin{array}{l}\text { Restriction fragment size } \\
(\mathrm{kb})\end{array}$} & \multirow{2}{*}{$\begin{array}{l}\text { Chromosome } \\
\text { size (Mb) }\end{array}$} \\
\hline & & $\mathrm{CeA}$ & $\mathrm{CeB}$ & $\mathrm{CeC}$ & $\mathrm{CeD}$ & \\
\hline CCUG $11256^{\mathrm{T}}$ & 1 & 1,655 & 1,120 & 894 & 644 & $4.31(4.35)$ \\
\hline ATCC 17589 & 1 & 1,700 & 1,200 & 783 & 649 & 4.33 \\
\hline B1SMN1 & 1 & 1,800 & 1,060 & 1,060 & 726 & $4.64(4.79)$ \\
\hline B2SMN1 & 1 & 1,870 & 1,060 & 970 & 667 & 4.57 \\
\hline S1MN1 & 1 & 1,923 & 1,060 & 970 & 649 & $4.60(4.90)$ \\
\hline ATCC 17587 & 2 & 1,976 & 1,190 & 713 & 571 & $4.45(4.53)$ \\
\hline ATCC 17591 & 2 & 1,960 & 1,185 & 708 & 567 & $4.42(4.62)$ \\
\hline ZoBell & 2 & 1,800 & 1,096 & 732 & 665 & $4.29(4.48)$ \\
\hline DSM 50227 & 3 & 1,660 & 928 & 873 & 730 & $4.19(4.19)$ \\
\hline AN11 & 3 & 1,560 & 1,060 & 1,006 & 668 & $4.29(4.43)$ \\
\hline AN10 & 3 & 1,750 & 1,144 & 955 & 650 & $4.50(4.52)$ \\
\hline ST27MN2 & 3 & 1,715 & 1,185 & 891 & 649 & $4.44(4.55)$ \\
\hline LSMN2 & 3 & 1,800 & 1,180 & 873 & 649 & $4.50(4.66)$ \\
\hline $\mathrm{CH} 88$ & 3 & 1,625 & 897 & 875 & 675 & 4.07 \\
\hline 19SMN4 & 4 & 2,812 & 646 & 564 & 315 & $4.34(4.55)$ \\
\hline ST27MN3 & 4 & 2,625 & 758 & 667 & 218 & $4.27(4.52)$ \\
\hline DNSP21 & 5 & 1,675 & 1,006 & 720 & 649 & $4.05(4.19)$ \\
\hline SP1402 & 6 & 1,544 & 1,422 & 587 & 507 & $4.06(4.12)$ \\
\hline LS401 & 6 & 1,575 & 1,465 & 578 & 515 & $4.13(4.02)$ \\
\hline DSM 50238 & 7 & 1,338 & 936 & 820 & 660 & $3.75(3.72)$ \\
\hline JM300 & & 1,630 & 1,130 & 1,009 & 263 & $4.03(4.19)$ \\
\hline
\end{tabular}

${ }^{a}$ Chromosome sizes are the sums of I-CeuI fragment sizes. The values in parentheses were obtained by comparing linearized chromosomes with Schizosaccharomyces pombe chromosomes.

electrophoresed under the optimal conditions for resolution of fragments in the megabase size range on a PFGE gel (Fig. 2). A single clear band was observed for almost all of the strains; nevertheless, in each case the brightest signal came from the DNA retained in the well, suggesting that a single circular chromosome constitutes the genome of $P$. stutzeri. When the resulting chromosome sizes were compared with the values obtained by adding the sizes of the I-CeuI fragments (Table 2), the greatest difference was $7 \%$. The discrepancies were due to the inherent limitations of fragment size calculations (e.g., small separation distances) and the lack of markers with sufficiently exact molecular weights in the megabase size range.

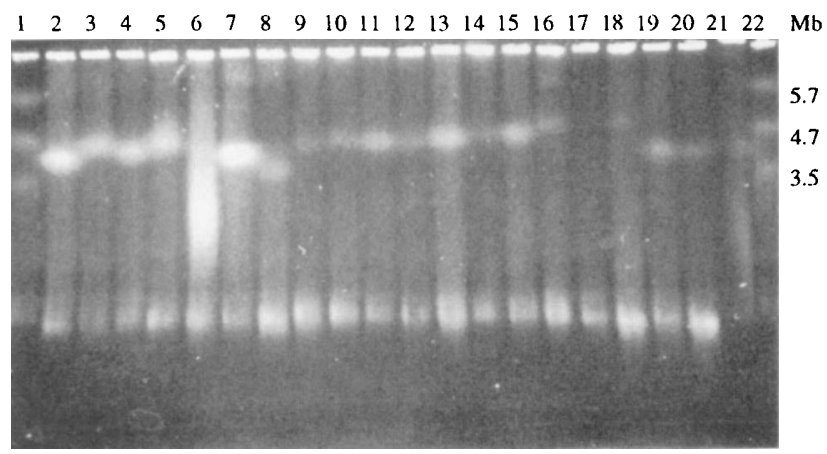

FIG. 2. Separation of undigested megabase pair replicons from $P$. stutzeri strains. Lanes 1 and 22, Schizosaccharomyces pombe; lane 2, DSM 50227; lane 3, ATCC 17587; lane 4, CCUG $11256^{\mathrm{T}}$; lane 5, ATCC 17591; lane 6, ATCC 17589; lane 7, DNSP21; lane 8, DSM 50238; lane 9, ZoBell; lane 10, 19SMN4; lane 11, ST27MN3; lane 12, AN11; lane 13, AN10; lane 14, ST27MN2; lane 15, LSMN2; lane 16, B1SMN1; lane 17, B2SMN1; lane 18, S1MN1; lane 19, SP1402; lane 20, LS401; lane 21, JM300. The separation conditions were as follows: linear pulse ramp from 2,000 to $4,500 \mathrm{~s}$ for $140 \mathrm{~h}$ at $1.3 \mathrm{~V} / \mathrm{cm}$ in a $0.6 \%$ agarose gel. A CHEF model DRII apparatus was used.
Genome architecture of $P$. stutzeri: I-CeuI skeleton and locations of $16 \mathrm{~S}$ rRNA, $23 \mathrm{~S}$ rRNA, ori, $\operatorname{rec} A, \operatorname{nos} Z$, and catA genes. I-CeuI digests of the 20 strains yielded four fragments, indicating that four copies of the $r r l$ gene are present in the $P$. stutzeri chromosome (Table 2 and Fig. 3), which was consistent with the results of the 23S rRNA and 16S rRNA fingerprints of $X b a \mathrm{I}$ - and SpeI-digested DNA. Consequently, the $\mathrm{I}-\mathrm{Ceu} \mathrm{I}$ site is present in all $P$. stutzeri $r r l$ genes and is not found in other parts of the chromosome or protected from digestion.

Similar I-CeuI patterns were observed in the same genomovar, with small size variations for the four fragments (Table 2 and Fig. 3). In strains B1SMN1, ATCC 17589, AN11, and DSM 50227 (genomovars 1 and 3), more pronounced deviations in size were observed for more than one fragment. When the patterns of the different genomovars were compared, a similar fragment size distribution seemed to be common to genomovars $1,2,3$, and 5 . Very different patterns were found for genomovars 4,6 , and 7, indicating that rRNA operon locations were not conserved within the species.

A limited set of housekeeping genes is used to define the backbone of the chromosome in bacteria (11). 16S rRNA, 23S rRNA, ori, and recA genes were localized on the I-CeuI fragments by hybridization. nos $Z$ and cat $A$ were also mapped as genes that are present in $P$. stutzeri. Hybridization patterns were conserved within genomovars. When the hybridization patterns of the genomovars were compared, the origin of replication was always located on the biggest fragment (fragment $\mathrm{CeA}$ ). However, different hybridization patterns were obtained with $16 \mathrm{~S}$ rRNA, $23 \mathrm{~S}$ rRNA, $\operatorname{rec} A, \operatorname{nos} Z$, and $c a t A$ probes for genomovars $2,4,6$, and 7 , while genomovars 1,3 , and 5 exhibited conserved hybridization patterns with these gene probes.

Intraspecies comparative mapping: low-resolution physical map of type strain CCUG 11256 with gene locations and I-CeuI cleavage maps of genomovar reference strains. To construct a low-resolution physical map, restriction enzymes that cut the DNA into 5 to 15 fragments were sought. The $\mathrm{G}+\mathrm{C}$ content of $P$. stutzeri CCUG $11256^{\mathrm{T}}$ ( $\mathrm{T}=$ type strain) has been reported to be $65 \mathrm{~mol} \%$ (68). Consequently, a total of 22 restriction enzymes, including enzymes that harbor AT-rich recognition sites of 6 or $8 \mathrm{bp}$ or the rare tetranucleotide CATG, were tested. The majority of these enzymes cleaved the DNA into more than 100 fragments. SwaI, PacI, and I-CeuI generated one, four, and four fragments, respectively, and were chosen for map construction. Single and double digests were characterized (Tables 3 and 4), which resulted in an average chromosome size of $4,336 \mathrm{~kb}$. A complete circular physical map was established from a single I-CeuI-PacI two-dimensional gel and data from double and single digests (Fig. 5). Hybridization of $16 \mathrm{~S}$ rRNA, 23S rRNA, nos $Z$, catA, ori, rec $A$, ssb, hemL, hemB, $o p r F$, and citA gene probes to fragments from single and double digests confirmed the established order of fragments and generated the data for a preliminary genetic map (Fig. 5).

Since differences in I-CeuI digests and gene hybridization patterns among $P$. stutzeri genomovars were found, I-CeuI cleavage maps were constructed in order to clarify the apparent variability of genome architecture. As determined from the conservation of the I-CeuI patterns and gene locations within genomovars, I-CeuI cleavage maps of the genomovar reference strains provided a representative model for each genomic group and revealed the diversity of genomic organization within the species. Because the order of only four fragments had to be determined, a partial-digest approach was chosen to construct the physical maps (Fig. 4). After partial I-CeuI digestion the fragments were hybridized with either $c a t A$ or $\operatorname{rec} A$. Identification of partial-digestion fragments by using molecu- 
A

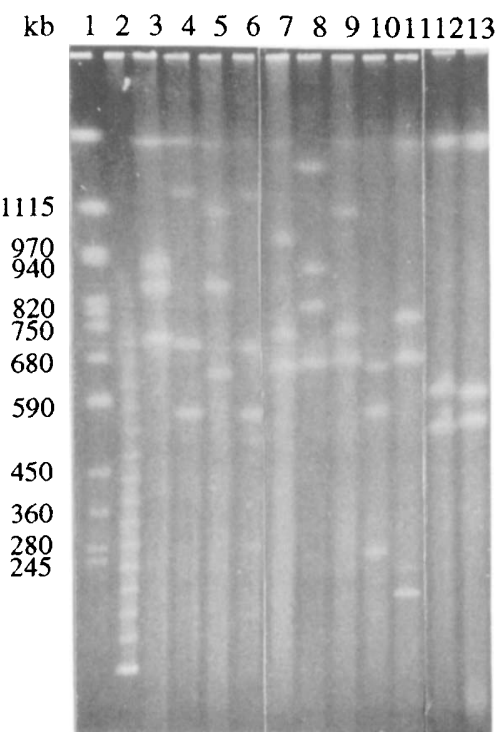

B

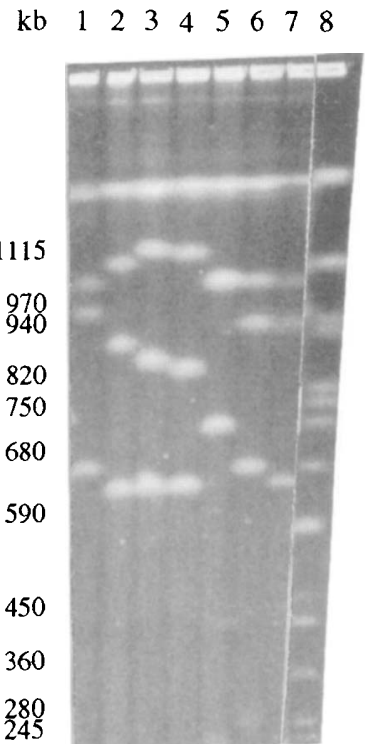

C

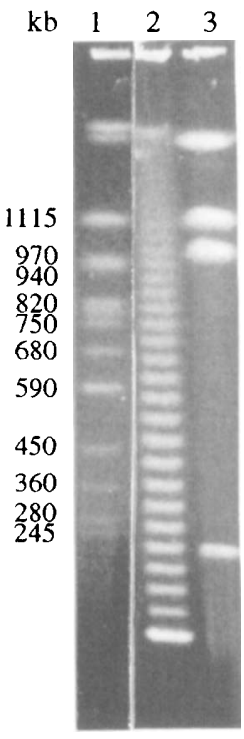

FIG. 3. I-CeuI digests of genomic DNAs from $P$. stutzeri strains. (A) Lane 1, Saccharomyces cerevisiae; lane 2, $\lambda$ DNA concatemers; lane 3, DSM 50227; lane 4, ATCC 17587; lane 5, CCUG 11256 ${ }^{\mathrm{T}}$; lane 6, ATCC 17591; lane 7, DNSP21; lane 8, DSM 50238; lane 9, ZoBell; lane 10, 19SMN4; lane 11, ST27MN3; lane 12, SP1402; lane 13, LS401. The running conditions were as follows: $6 \mathrm{~V} / \mathrm{cm}$; reorientation angle, $120^{\circ}$; pulse times, 40 to $150 \mathrm{~s}$ for $50 \mathrm{~h}$; agarose concentration, $1.5 \%$; CHEF model DRIII apparatus. (B) Lane 1, AN11; lane 2, AN10; lane 3, ST27MN2; lane 4, LSMN2; lane 5, B1SMN1; lane 6, B2SMN2; lane 7, S1MN1; lane 8, Saccharomyces cerevisiae. The running conditions were as follows: $170 \mathrm{~V}$; pulse times, 50 to $160 \mathrm{~s}$ for $53 \mathrm{~h}$; agarose concentration, $1.5 \%$; Gene Navigator unit. (C) Lane 1, Saccharomyces cerevisiae; lane 2, $\lambda$ DNA concatemers; lane 3, JM300. The running conditions were as follows: $3.3 \mathrm{~V} / \mathrm{cm}$; pulse times, 70 to 350 for $70 \mathrm{~h}$; agarose concentration, $1 \%$; CHEF model DRII apparatus.

lar weight and gene probe signals resulted in seven I-CeuI cleavage maps, one for each genomovar reference strain (Fig. $5)$. Due to the ambiguous direction of the physical maps caused by the lack of a genetic map or other references, the $r e c A$ gene was arbitrarily placed on the left side with respect to the origin of replication.

The positions of the rRNA genes clearly differ among the genomovars. In the case of strains CCUG $11256^{\mathrm{T}}$, ATCC 17591, DSM 50227, DNSP21, and DSM 50238 (genomovars 1, $2,3,5$, and 7, respectively), rRNA genes are not clustered around the origin of replication and are almost equally distributed around the chromosome. In strain SP1402 (genomovar 6), three operons are located in a region that corresponds to $26 \%$ of the genome, and a fourth operon is on the opposite side of the chromosome. Two rRNA operons are thought to be on each side of ori in these strains. In strain 19SMN4 (genomovar $4), r m$ operons are grouped in a limited chromosome region (36\% of the chromosome), but they are unequally distributed with respect to the origin of replication. There are no indications of differences in gene order in the low-resolution maps for the genomovar 1,3 , and 5 reference strains, but positions and gene order are remarkably altered in genomovars $2,4,6$, and 7 compared with genomovars 1,3 , and 5 , suggesting that several rearrangements have occurred. $s s b$ is at a different position in strains ATCC 17591 and 19SMN4. The nos $Z$ and cat $A$ locations are altered in strain SP1402, while in addition $s s b$ also occupies a different position in strain DSM 50238.

$P$. stutzeri JM300: a new genomovar? I-CeuI digestion of JM300 genomic DNA also yielded four fragments but generated a fragment size distribution different from the distributions observed with the seven genomovars. The positions of the $16 \mathrm{~S}$ rRNA, 23S rRNA, nos $Z$, cat $A, \operatorname{rec} A$, and or $i$ genes were unique on the JM300 I-CeuI map (Fig. 5), indicating that the organization of the JM300 chromosome does not correspond to the genomic model of any existing genomovar. Since distinction between genomovars on the basis of genome organization seems to be possible, JM300 could not belong to any of the previously described genomovars.

\section{DISCUSSION}

In this study we included a considerable number of strains which represent all of the genomovars of $P$. stutzeri and which had different sources and dates of isolation. These strains constitute the most extensively studied group of $P$. stutzeri strains in taxonomic and systematic terms $(4,68,69,71,72)$.

Variation in chromosome size has been found in $P$. stutzeri, and the chromosome sizes range from 3.75 to $4.64 \mathrm{Mb}$. The $P$. stutzeri genome is smaller than the genome of its close relative $P$. aeruginosa, whose size has been reported to range from 5.2 to $7 \mathrm{Mb}(75)$. The genome sizes of $P$. stutzeri are not consistent with values determined previously for some of the strains included in this study. Differences of up to $1.6 \mathrm{Mb}$ have been found with sizes calculated by renaturation kinetics (14). Smaller differences (up to $670 \mathrm{~kb}$ ) were found with values reported by Rainey et al. (61); underestimating genome size in this case was probably a consequence of the presence of doublets and triplets in the SpeI restriction patterns used for genome size estimates by these authors. Adding I-CeuI fragment sizes and determining the size of the whole chromosome are more reliable measures. We found length variations in all four I-CeuI fragments within genomovars which ranged between 8 and $288 \mathrm{~kb}$. While DNA rearrangements can explain the variability, DNA segments between the four $r m$ genes must also have been lost or gained. In this case, we expect that a mosaiclike structure would be found when a more detailed analysis of the $P$. stutzeri chromosome is performed. This view is supported by the high degree of heterogeneity of the $X b a \mathrm{I}$ and 


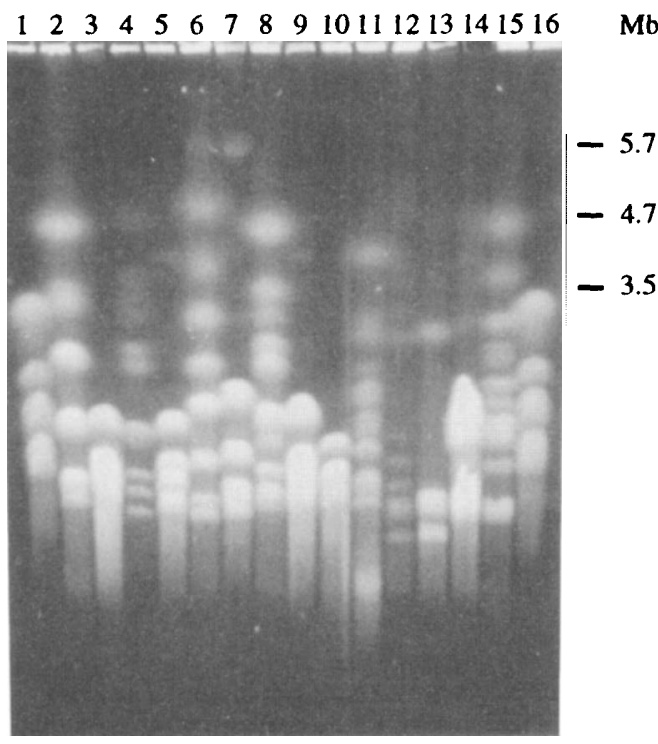

FIG. 4. I-CeuI complete and partial digests of DNAs of genomovar reference strains of $P$. stutzeri. Lanes 1 and 16, Candida albicans; lane 2, partial digest of DSM 50227 DNA; lane 3, complete digest of DSM 50227 DNA; lane 4, partial digest of CCUG $11256^{\mathrm{T}}$ DNA; lane 5, complete digest of CCUG $11256^{\mathrm{T}} \mathrm{DNA}$; lane 6, partial digest of ATCC 17591 DNA; lane 7, complete digest of ATCC 17591 DNA; lane 8, partial digest of DNSP21 DNA; lane 9, complete digest of DNSP21 DNA; lane 10, complete digest of DSM 50238 DNA; lane 11, partial digest of DSM 50238 DNA; lane 12, partial digest of 19SMN4 DNA; lane 13, complete digest of 19SMN4 DNA; lane 14, complete digest of SP1402 DNA; lane 15, partial digest of SP1402 DNA. The positions and sizes of the Schizosaccharomyces pombe chromosomes are indicated on the right. The running conditions were as follows: linear pulse ramp from 800 to $3,000 \mathrm{~s}$ for $140 \mathrm{~h}$ at $55 \mathrm{~V}$ in a $0.6 \%$ agarose gel. A Gene Navigator unit from Pharmacia LKB was used.

SpeI fingerprints which did not reflect the genomovar division. Evidence of mosaic structures has been found in $P$. aeruginosa (75). Natural transformation has been found in $P$. stutzeri (50), and plasmids are known to be common in this species (73; this study). Plasmids (or parts of plasmids) can be stabilized by integration into the Pseudomonas genome (29, 30, 76). Two genes of metabolic pathways which are thought to be related to lateral transfer $(29,84)$ have been found to be chromosomally encoded in $P$. stutzeri; cat $A$ codes for a catechol oxygenase I (38), a key enzyme in the metabolism of benzoate and other aromatic compounds, and $\operatorname{nos} Z$, the nitrous oxide reductase gene (12), is a gene that has been implicated in nitrous oxide respiration. It has been proposed that incorporation of foreign DNA carried by plasmids into the chromosome of a common ancestor occurred during evolution of two species of the same genus, $P$. putida and $P$. aeruginosa $(29,30)$. Transposons have been detected in different Pseudomonas species (30, 76), al-

TABLE 3. Fragment sizes in single restriction enzyme digests of P. stutzeri CCUG $11256^{\mathrm{T}} \mathrm{DNA}$

\begin{tabular}{lrcr}
\hline \multirow{2}{*}{ Fragment } & \multicolumn{3}{c}{ Size $(\mathrm{kb})$} \\
\cline { 2 - 4 } & PacI & SwaI & I-CeuI \\
\hline A & 1,700 & 4,350 & 1,655 \\
B & 1,306 & & 1,120 \\
C & 1,253 & & 894 \\
D & 84 & & 644 \\
Total & 4,343 & 4,350 & 4,313 \\
\hline
\end{tabular}

TABLE 4. Fragment sizes in double restriction enzyme digests of P. stutzeri CCUG $11256^{\mathrm{T}}$ DNA

\begin{tabular}{lccc}
\hline \multirow{2}{*}{ Fragment } & \multicolumn{3}{c}{ Size $(\mathrm{kb})$} \\
\cline { 2 - 4 } & PacI + I-CeuI & SwaI + I-Ceu $\mathrm{I}$ & PacI + Swa I \\
\hline 1 & 1,226 & 1,655 & 1,394 \\
2 & 1,092 & 1,120 & 1,306 \\
3 & 859 & 890 & 1,253 \\
4 & 610 & 339 & 306 \\
5 & 456 & 306 & 84 \\
6 & 48 & & \\
7 & 34 & & \\
8 & 33 & & 4,343 \\
Total & 4,358 & 4,310 & \\
\hline
\end{tabular}

though none has been described for $P$. stutzeri. We suggest that removal and addition of plasmid DNA, transposition, and natural transformation are mechanisms by which changes have occurred in the $P$. stutzeri genome and have generated part of the genotypic and phenotypic diversity exhibited by the genomovars and individual strains. Diversification by the mechanisms indicated above starts at the level of clonal variants. The differences in chromosome size and the small differences between the melting temperatures of homologous hybrids and the melting temperatures of heterologous hybrids $\left(\Delta T_{m}\right.$ values) $\left(0.2^{\circ} \mathrm{C}\right.$ between strains $19 \mathrm{SMN} 4$ and ST27MN3; $0.0^{\circ} \mathrm{C}$ between ATCC 17587 and ATCC 17591) (68) make the hypothesis that point mutations are the first step of diversification unlikely.

Examples of the impact of "small-scale" genome rearrangements in P. stutzeri are strains ATCC 17589 and CCUG $11256^{\mathrm{T}}$ of genomovar 1 . The high degree of variability of restriction patterns cannot be related only to nucleotide divergence since a $\Delta T_{m}$ value of $0.0^{\circ} \mathrm{C}$ and an evolutionary distance of 0.3 have been reported for these two strains $(4,68)$. The 30 -kb difference in chromosome size is not enough to explain acquisition or loss of XbaI and SpeI sites. Strain ATCC 17589 has a peculiar I-CeuI pattern within genomovar 1 and is the only exception to homogeneity of hybridization patterns. $r e c A$ hybridized with fragment $\mathrm{CeB}$ in this strain, while this gene was localized in fragment $\mathrm{CeC}$ in the other strains of this genomovar. The RFLPs observed in P. stutzeri strains are a testimony to the genomic plasticity of this species. As proposed by Hall (26), DNA rearrangements may be responsible for a high proportion of the RFLPs used to differentiate and type bacteria.

In this paper we describe the construction of the first lowresolution physical map and a preliminary genetic map of $P$. stutzeri CCUG $11256^{\mathrm{T}}$. Also, I-CeuI cleavage maps of representative strains of the seven genomovars of $P$. stutzeri, as well as an I-CeuI cleavage map of strain JM300, were constructed. As in most procaryotes, a unique circular chromosome constitutes the genome of $P$. stutzeri. A similar backbone organization of $r r n$ operons was found within the genomovars, along with conserved locations of four genes. Strains belonging to a genomovar are defined by $\Delta T_{m}$ values of $2^{\circ} \mathrm{C}$ or less (68). These results suggest that there may be a correlation between genome organization and genetic relatedness. A comparison of I-CeuI cleavage maps revealed that the $r m$ backbone and gene order are not conserved among genomovars. The genome organizations of genomovars 1,3 , and 5 seem to be very similar within the low resolution of the maps. Genomovars 5 and 1 are the most closely related genomovars as determined by $16 \mathrm{~S}$ rRNA data (4) and DNA-DNA hybridization data (68). The 

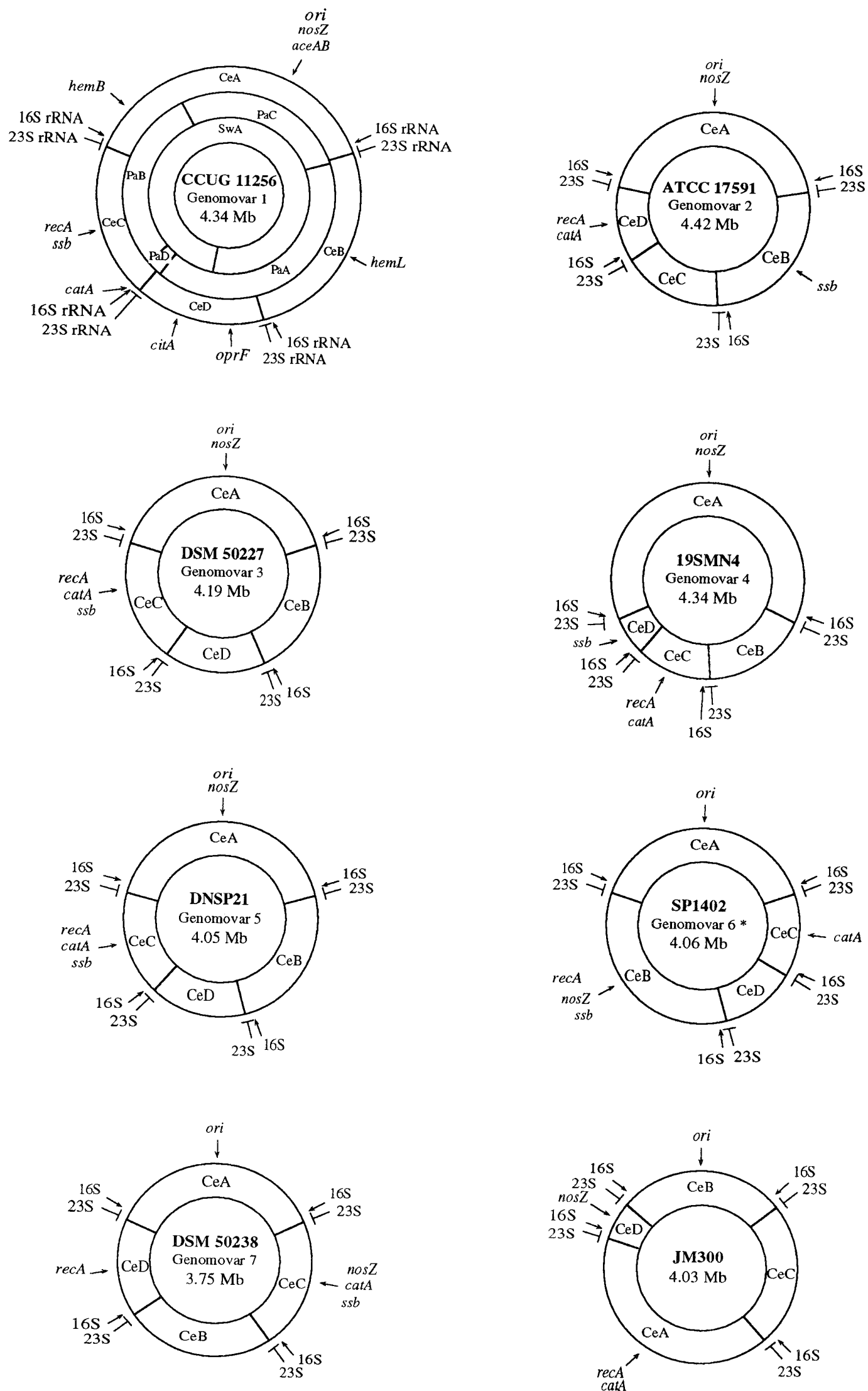

FIG. 5. Physical map of the chromosome of $P$. stutzeri type strain CCUG 11256 and I-CeuI cleavage maps of genomovar reference strains and strain JM300. Restriction sites for I-CeuI, PacI, and SwaI are indicated. The positions of mapped genes and $r m$ operons are shown on the circular maps. The positions of genes are indicated by arrows spanning the centers of the fragments where they are located. Genomovar 6 has been renamed $P$. balearica. Abbreviations: $16 \mathrm{~S}$, $16 \mathrm{~S}$ rRNA gene; 23S, $23 S$ rRNA gene. 
chromosome structures of the genomovar $2,4,6$, and 7 reference strains and strain JM300 are obviously distinct, as shown by rRNA operon locations and gene positions. The most different maps are the maps of strains SP1402 (genomovar 6), DSM 50238 (genomovar 7), and JM300. Genomovar 6 has been found to be the most distantly related genomovar by $16 \mathrm{~S}$ rRNA sequence comparisons and has been designated a new species, $P$. balearica (4). Among the rest of the genomovars, genomovar 7 exhibited the greatest evolutionary distance (4). Strain DSM 50238 was also the most phenotypically and genotypically aberrant strain in the study of Rossello et al. (68). We also propose that strain JM300 does not belong to any of the previously described genomovars. Phylogenetic and taxonomic data (70) are consistent with our results which show that a new genomovar (genomovar 8) should be created, with JM300 as the reference strain. In conclusion, it seems to be possible to distinguish the genomovars on the basis of genome organization. I-CeuI digests have been shown to be a powerful tool for analyzing gross genome structure and for comparative mapping. The taxonomic criteria provided by map comparisons resulted in conclusions consistent with the division of $P$. stutzeri into seven genomovars. We think that the results which we obtained, even though our maps are rudimentary, should have significance for understanding chromosome structure and genome evolution and should confirm that bacterial genome structure has great potential in the field of bacterial taxonomy and systematics.

We demonstrated that I-CeuI cuts the $r l$ gene of $P$. stutzeri and no other sites. The number of rRNA operons is conserved within $P$. stutzeri, but the locations are not conserved, in contrast to Salmonella enterica $(43,45,48)$ and $P$. aeruginosa $(75)$. As in $P$. aeruginosa (75), four $r r$ operons are present in all strains, but these operons occur at different positions with respect to the origin of replication. In genomovars $1,2,3,5$, and 7, rRNA operons are equally distributed around the chromosome. To date, this arrangement does not seem to be common among procaryotes. In the species that have been analyzed, the rrn operons are grouped in a region corresponding to 37 to $52 \%$ of the chromosome around ori (41). In genomovar 4 , the $r r n$ operons are grouped in a limited chromosome region ( $36 \%$ of the chromosome) but are distant from the origin of replication. However, in strain JM300 the rRNA operons cluster in a region corresponding to $59 \%$ of the genome around ori. In all of the genomovars except genomovar 4, the $r m$ operons are distributed in two groups of two operons on each side of ori, in contrast to most procaryotes, in which the rrn operons are unequally distributed (11). All of the $r n$ operons supposedly are transcribed divergently away from ori.

In bacteria, the origin of replication is situated almost diametrically opposite the terminus of replication (11), resulting in two replication arms of similar lengths. rRNA operons are generally transcribed divergently away from the origin of replication (11) and are oriented in such a way that transcription occurs in the same direction as replication (6). If the same arrangement occurs in $P$. stutzeri, the terminus of replication should be situated in the region delimited by the two rRNA operons with inverted orientations (fragment $\mathrm{CeD}$ in strains CCUG $11256^{\mathrm{T}}$, DSM 50227, DNSP21, and SP1402; fragment CeB in strains 19SMN4 and DSM 50238; and fragment CeC in strain ATCC 17591).

Different kinds of genetic events (deletions, insertions, translocations) may have played a role in the generation of the different genome structures of genomovars from an ancestor. However, gross genome changes, such as large inversions (recombinations) which restructure the whole chromosome, can explain for the most part the different genomic arrangements found in the genomovars. As a working model, an ancestor chromosome which had genes and rRNA operons arranged in the order found in strains CCUG $11256^{\mathrm{T}}$, DSM 50227, and DNSP21 (genomovars 1, 3, and 5) is proposed (Fig. 6A and C). Strains CCUG $11256^{\mathrm{T}}$, DSM 50227, and DNSP21 have the same rRNA backbone, which may be similar to the situation before $P$. stutzeri branched into genomovars. The genome structures of all of the genomovars might be deduced from this ancestral chromosome. Below we outline possible patterns of evolution that could have yielded some of the different genome organizations. Genomovar 4 and genomovar 2 gross genome structures could have differed by a single large inversion between fragments $\mathrm{CeA}$ and $\mathrm{CeB}$, including one rRNA operon, $s s b$, and the origin of replication (Fig. 6B). The symmetry of the origin of replication relative to the terminus would not have been highly altered according to this model; nevertheless, there is a displacement of genes outside the inverted segment relative to ori. Evolution of genomovar 4 from genomovar 2 would be consistent with the close relationship of these two genomovars determined by $16 \mathrm{~S}$ rRNA analysis and DNADNA hybridization $(4,68)$. The changes observed in strains SP1402 and DSM 50238 (genomovars 6 and 7, respectively) and in strain JM300 must be more complex than a simple inversion. For example, genomovar 6 genome structure could have resulted from three consecutive inversions from the ancestor (Fig. 6C). A first large inversion, between fragments $\mathrm{CeC}$ and $\mathrm{CeB}$ of the ancestor, would have placed $r e c A$ and $s s b$ on the opposite side of the chromosome. A second large inversion, between the generated $\mathrm{CeA}^{\prime}$ and $\mathrm{CeB}^{\prime}$ fragments, including one rRNA operon, the origin of replication, $s s b$, and $\operatorname{rec} A$, would have yielded fragments $\mathrm{CeA}$ and $\mathrm{CeB}$ of SP1402. A third inversion, between fragments $\mathrm{CeC}^{\prime}$ and $\mathrm{CeD}^{\prime}$, would have shifted the catA location and the rRNA operon orientation, yielding fragments CeD and CeC from SP1402. This third change would have been initiated by the significant asymmetry of the origin of replication relative to the terminus caused by the second inversion, and it would have implicated the terminus of replication resembling inversions found in Salmonella typhi Ty2 (47) and E. coli K-12 (58). Inversions proposed for genome evolution of strain SP1402 (genomovar 6) affect large regions of the genome and would greatly alter gene dosage and symmetry of the origin with respect to the terminus of replication. In general, it has been thought that the rate of occurrence of inversions is low compared with other kind of rearrangements, but studies have been limited to a few species and some of the species used are known to live in a restricted environment, which might explain their remarkable evolutionary stability $(43,45,62)$. However, there is increasing evidence from recent map comparisons that chromosomal inversions might shape the genomes of species or subspecies. Fossilized inversions have been characterized recently $(19,41,42,45,47$, 62 ), and evidence of such rearrangements has also been found in other microorganisms $(9,13,39,49,59,83)$, indicating that inversions are not seldom established in natural populations. Natural inversions are not necessarily consistent with the rules that control E. coli or Salmonella typhimurium inversions under laboratory conditions $(37,52)$. Hill et al. (28) and François et al. (21) easily obtained revertants from inverted chromosomes when bacteria were grown rapidly in rich media. But this situation is probably unusual for many microorganisms which have to adapt to different, harsh environmental conditions and usually have low rates of growth in nature. Growth rate alone, as determined in the laboratory, could never be the only factor that determines survival and successful spread in natural environments. Interestingly, all naturally occurring inversions that have been described, such as those thought to generate the 
A)

Genomovar 1

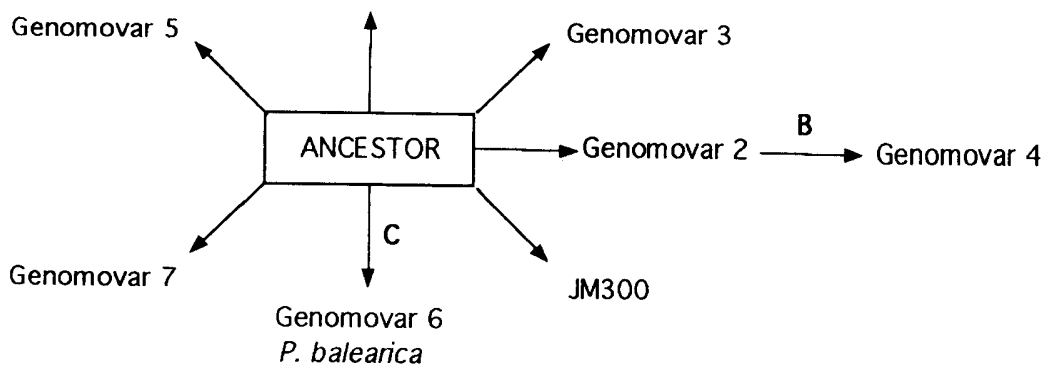

B)

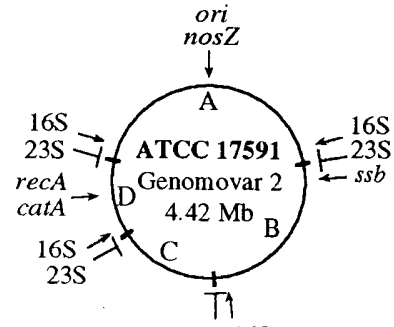

23S $16 \mathrm{~S}$
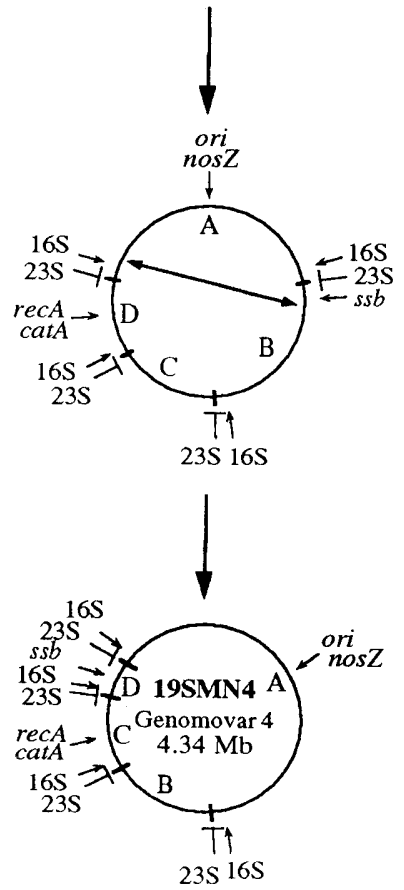

C)
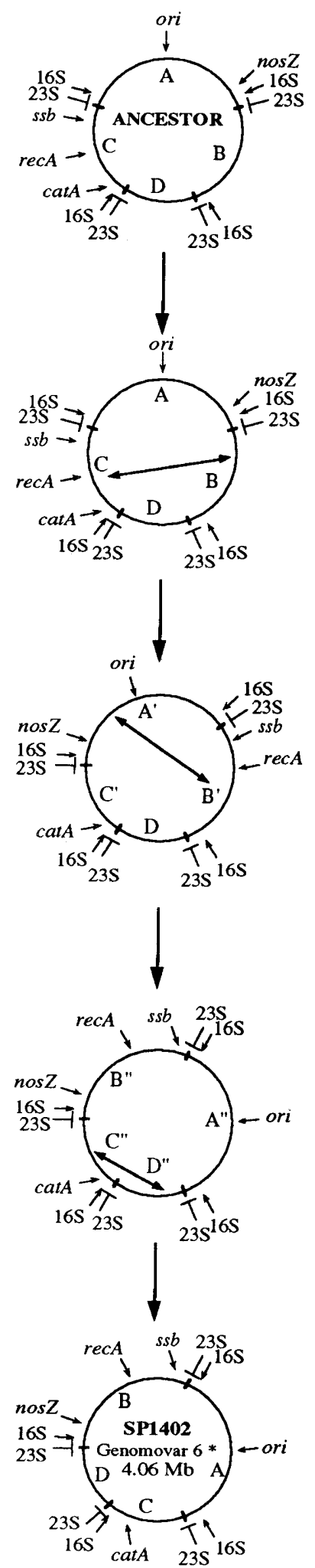

FIG. 6. (A) Generation of $P$. stutzeri genomovars: $P$. stutzeri diversification from a common ancestor on different lines of evolution. The ancestor would have I-CeuI fragments and genes arranged in the order found in strains CCUG $11256^{\mathbf{T}}$ (genomovar 1), DNSP21 (genomovar 5), and DSM 50227 (genomovar 3). (B) Possible evolutionary pathway for creating genomovar 4 genome structure from genomovar 2. (C) Possible evolutionary pathway for creating genomovar $6(P$. balearica) genome structure from the ancestor (for explanation, see the text). Abbreviations: 16S, 16S rRNA gene; 23S, 23S rRNA gene. 
chromosome structures of genomovars 4 and 6 , include the origin or the terminus of replication, and none is within a replication arm. These kinds of inversions should respect direction of transcription of genes. We do not know the rules that select inversions in natural populations; however, rearranged chromosomes must offer an advantage under environmental conditions, probably because of modifications to phenotypes $(27,28,37)$ or modulations of gene expression $(20)$. neersions can also be responses of genomes to imbalances produced by other rearrangements, such as duplications, insertions, or deletions, or vice versa. Liu et al. proposed that inversions in Salmonella typhi and Salmonella enteridis could be caused by the 118 - and $100-\mathrm{kb}$ insertions in their respective genomes $(45,46)$. Cascades of rearrangements have been also reported for Bacillus subtilis (1). Bacterial genomes that undergo natural transformation like $P$. stutzeri could be more prone to such rearrangements, as has been proposed for Campylobacter strains (78). Homologous recombination between inverted repeated DNA sequences is a common mechanism for generating inversions. Inversions due to recombination between rRNA operons have been described (19, 28, 42, 46 ), but such inversions do not seem to have occurred during $P$. stutzeri evolution. Other recurrent chromosomal elements, such as insertion sequences (36), $t-R N A$, and $r h s$, or simple sequences were probably involved in generating the rearrangements suggested in this study.

Fonstein and Haselkorn (18) proposed that there are two levels of genome conservation in bacteria. Microorganisms with strict conservation of gene order, like $E$. coli $(5,58)$, Salmonella enterica $(43,45,48)$, Clostridium perfringens (7), Streptomyces spp. (40), Borrelia spp. (56), Haloferax spp. (49), Lactococcus lactis (41), and Mycoplasma spp. (39, 59), form one group. Significant pressure must exist to maintain these stable chromosome structures. A second group includes microorganisms with highly rearranged chromosomes and no longrange conservation of genetic maps, such as $B$. cereus (9), $H$. pylori (35), and $R$. capsulatus (19). The large variation found among fingerprints and all of the genomovar maps indicates that genome organization is not conserved within $P$. stutzeri and that chromosome rearrangements are frequent in this species. For these reasons, we propose that $P$. stutzeri should be assigned to the second group of microorganisms. Considering the apparent plasticity of the $P$. stutzeri chromosome, we think that it would not be surprising to find more differences when more genes are localized. At least for one strain of genomovar 3 , additional hybridization data revealed differences which suggested that large changes have occurred (data not shown).

Divergence within $P$. stutzeri, which is a widespread microorganism, may have occurred recently during colonization and adaptation to different environments or even microenvironments, as suggested recently by Schmidt et al. (75). Diversification of this species could be the result of niche-specific selection of (i) point mutations in genes, which cause gradually nucleotide divergence (considerable sequence divergence has occurred during evolution of $P$. stutzeri genomovars, as shown by $\mathrm{G}+\mathrm{C}$ contents [68], $\Delta T_{m}$ values between 5.1 and $12.2^{\circ} \mathrm{C}$ [68], and evolutionary distances [4]), (ii) acquisition of new genes necessary to survive under environmental conditions by horizontal transfer of plasmids and transposons or via natural transformation that modifies the genetic content and size of the genome, (iii) short-range recombinations within genes that alter specificities, and (iv) large chromosome rearrangements that affect the three-dimensional structure of the nucleoid and probably its function. $P$. stutzeri evolution and diversification could be the result of independent genomic adaptations of an ancestor to different environmental pressures exerted by niches which are difficult to trace. Environmentally adapted organisms, such as $P$. stutzeri and the human pathogenic bacterium $H$. pylori (35), which seems to exhibit unusual genome instability, should provide a novel view of the chromosome.

\section{ACKNOWLEDGMENTS}

A fellowship from the Ministerio de Educación y Ciencia (Spain) to M.G. is gratefully acknowledged. This work was supported by grants from CICYT (Spain) and the Deutsche Forschungsgemeinschaft (Germany).

M.G. and J.L. gratefully acknowledge Ricardo Amils and workers in his laboratory for an introduction to PFGE techniques. We also thank R. Rosselló for interesting discussions.

\section{REFERENCES}

1. Anagnostopoulos, C. 1990 . Genetic rearrangenents in Bacillus subtilis, p. 361-371. In K. Drlica and M. Riley (ed.), The bacterial chromosome. American Society for Microbiology, Washington, D.C.

2. Baggi, G., P. Barbieri, E. Galli, and S. Tollari. 1987. Isolation of a Pseudomonas stutzeri strain that degrades $O$-xylene. Appl. Environ. Microbiol. 53: 2129-2132.

3. Baya, A. M., P. R. Brayton, V. L. Brown, D. J. Grimes, E. Russek-Cohen, and R. R. Colwell. 1986. Coincident plasmids and antimicrobial resistance in marine bacteria isolated from polluted and unpolluted Atlantic Ocean samples. Appl. Environ. Microbiol. 51:1285-1292.

4. Bennasar, A., R. Rosselló-Mora, J. Lalucat, and E. R. B. Moore. 1996. 16S rRNA sequence analysis relative to genomovars of Pseudomonas stutzeri and proposal of Pseudomonas balearica sp. nov. Int. J. Syst. Bacteriol. 46:200205.

5. Birkenbihl, R. P., and W. Vielmetter. 1989. Cosmid-derived map of Escherichia coli strain BHB2600 in comparison to the map of strain W3110. Nucleic Acids Res. 17:5057-5069.

6. Brewer, B. J. 1990. Replication and transcriptional organization of the Escherichia coli chromosome, p. 61-83. In K. Drlica and M. Riley (ed.), The bacterial chromosome. American Society for Microbiology, Washington, D.C.

7. Canard, B., B. Saint-Joanis, and S. T. Cole. 1992. Genomic diversity and organization of virulence genes in the pathogenic anaerobe Clostridium perfringens. Mol. Microbiol. 6:1421-1429.

8. Carlson, C. A., L. S. Pierson, J. J. Rosen, and J. L. Ingraham. 1983. Pseudo monas stutzeri and related species undergo natural transformation. J. Bacteriol. 153:93-99.

9. Carlson, C. R., A. Gronstad, and A.-B. Kolsto. 1992. Physical maps of the genomes of three Bacillus cereus strains. J. Bacteriol. 174:3750-3756.

10. Church, G. M., and W. Gilbert. 1984. Genomic sequencing. Proc. Natl. Acad Sci. USA 81:1991-1995.

11. Cole, S. T., and I. Saint Girons. 1994. Bacterial genomics. FEMS Microbiol. Rev. 14:139-160.

12. Coyle, C. L., W. G. Zumft, P. M. H. Kroneck, H. Körner, and W. Jakob. 1985 Nitrous oxide reductase from denitrifying Pseudomonas perfectomarina: purification and properties of a novel multicopper enzyme. Eur. J. Biochem. 153:459-467.

13. Dempsey, J. A. F., A. B. Wallace, and J. G. Cannon. 1995. The physical map of the chromosome of a serogroup A strain of Neisseria meningitidis shows complex rearrangements relative to the chromosomes of two mapped strains of the closely related species N. gonorrhoeae. J. Bacteriol. 177:6390-6400.

14. Döhler, K., V. A. R. Huss, and W. G. Zumft. 1987. Transfer of Pseudomonas perfectomarina Baumann, Bowditch, Baumann, and Beaman 1983 to Pseudomonas stutzeri (Lehmann and Neumann 1896) Sijderius 1946. Int. J. Syst. Bacteriol. 37:1-3.

15. Donald, L. J., G. F. Molgat, and H. W. Duckworth. 1989. Cloning, sequencing, and expression of the gene for NADH-sensitive citrate synthase of Pseudomonas aeruginosa. J. Bacteriol. 171:5542-5550.

16. Eckhardt, T. 1978. A rapid method for identification of plasmid deoxyribonucleic acid in bacteria. Plasmid 1:584-588.

17. Ferguson, S. T. 1994. Denitrification and its control. Antonie Leeuwenhoek 66:89-110.

18. Fonstein, M., and R. Haselkorn. 1995. Physical mapping of bacterial ge nomes. J. Bacteriol. 177:3361-3369.

19. Fonstein, M., T. Nikolskaya, and R. Haselkorn. 1995. High-resolution alignment of a 1-megabase-long genome region of three strains of Rhodobacter capsulatus. J. Bacteriol. 177:2368-2372.

20. Fonstein, M., T. Nikolskaya, D. Zaporojets, Y. Nikolsky, S. Kulakauskas, and A. Mironov. 1994. Tn 10 -mediated inversions fuse uridine phosphorylase $(u d p)$ and rRNA genes of Escherichia coli. J. Bacteriol. 176:2265-2271.

21. François, V., J. Louarn, J.-E. Rebollo, and J.-M. Louarn. 1990. Replication termination, nondivisible zones, and structure of the Escherichia coli chromosome, p. 335-340. In K. Drlica and M. Riley (ed.), The bacterial chromosome. American Society for Microbiology, Washington, D.C. 
22. Fujita, M., M. Futai, and A. Amemura. 1990. In vivo expression of the Pseudomonas stutzeri maltotetraose-forming amylase gene $(a m y P)$. J. Bacteriol. 172:1595-1599.

23. Gauthier, A., M. Turmel, and C. Lemieux. 1991. A group I intron in the chloroplast large subunit rRNA gene of Chlamvdomonas eugametos encodes a double-strand endonuclease that cleaves the homing site of this intron. Curr. Genet. 19:43-47.

23a.Genschel. J. Unpublished data.

24. Gorton, T. S., M. S. Goh, and S. J. Geary. 1995. Physical mapping of the Mycoplasma gallisepticum S6 genome with localization of selected genes. J. Bacteriol. 177:259-263.

25. Grothues, D., and B. Tümmler. 1991. New approaches in genome analysis by pulsed-field gel electrophoresis: application to the analysis of Pseudomonas species. Mol. Microbjol. 5:2763-2776.

26. Hall. L. M. C. 1994. Are point mutations or DNA rearrangements respon sible for the restriction fragment length polymorphisms that are used to type bacteria? Microbiology 140:197-204.

27. Haselkorn, R. 1992. Developmentally regulated gene rearrangements in prokaryotes. Annu. Rev. Genet. 26:111-128.

28. Hill, C. W. S. Harvey, and J. A. Gray, 1990. Recombination between rRNA genes in Escherichia coli and Salmonella tvphimurium. p. 335-340. In K. Drlica and M. Riley (ed.). The bacterial chromosome. American Socicty for Microhiology. Washington, D.C

29. Hollowav, B. W., S. Dharmsthiti, V. Krishnapillai, A. F. Morgan, V. Obeyesekere, E. Ratnaningsih, M. Sinclair, D. Strom, and C. Zhang. 1990. Patterns of gene linkages in Pseudomonas species, p. 97-105. In K. Drlica and M. Riley (ed.), The bacterial chromosome. American Society for Microhiology. Washington. D.C.

30. Holloway, B. W., and A. F. Morgan. 1986. Genome organization in Pseudo monas. Annu. Rev. Microbiol. 40:79-105.

31. Holloway, B. W., U. Römling, and B. Tümmler. 1994. Genomic mapping of Pseudomonas aenuginosa PAO. Microbiology 140:2907-2929.

32. Holmes. B. 1986. Identification and distribution of Pseudomonas stutzeri in clinical material. J. Appl. Bacteriol. 60:401-411.

33. Honevcutt, R. J., M. McClelland, and B. W. S. Sobral. 1993. Physical map of the genome of Rhizobium meliloti 1021. J. Bacteriol. 175:6945-6952.

34. Hungerer, C., B. Troup, U. Römling, and D. Jahn. 1995. Cloning, mapping and characterization of the Pseudomonas aeruginosa hemL gene. Mol. Gen. Genet. 248:375-380)

34a.Jahn, D. Unpublished data

35. Jiang, Q., K. Hiratsuka, and D. E. Taylor. 1996. Variability of gene order in different Helicobacter pylori strains contributes to genome diversity. Mol. Microbiol. 20:833-842.

36. Komoda, Y., M. Enomoto, and A. Tominaga. 1991. Large inversion in Escherichia coli K-12 1485IN between inversely oriented IS3 elements near lac and $c d d$. Genetics 129:(639-645.

37. Kraviec, S., and M. Riley. 1990. Organization of the bacterial chromosome. Microbiol. Rev. 54:502-539.

38. Kukor, J. J., R. H. Olsen, and D. P. Ballou. 1988. Cloning and expression of the cat $A$ and the catBC gene clusters from Pseudomonas aeruginosa PAO.J Bacteriol. 170:4458-4465.

39. Ladefoged, S. A., and G. Christiansen. 1992. Physical and genetic mapping of the genomes of five Mvcoplasma hominis strains by pulsed-field gel electrophoresis. J. Bacteriol. 174:2199-2207.

40. Leblond, P. M. Redenbach, and J. Cullum 1993. Physical map of the Streptomyces lividans of chromosome and comparison with that of related strain Streptomvces coelicolor A3. J. Bacteriol. 175:3422-3429.

41. Le Bourgeois, P., M. Lautier, L. Van der Berghe, M. J. Gasson, and P. Ritzenthaler. 1995. Physical and genetic map of the Lactococcus lactis subsp. cremoris MG1363 chromosome: comparison with that of Lactococcus lactis subsp. lactis IL 1403 reveals a large genome inversion. J. Bacteriol. 177:2840) 2850

42. Liu, S.-H., and K. E. Sanderson. 1995. The chromosome of Salmonella paratyphi $\mathrm{A}$ is inverted by recombination between $r n H$ and $m$. $G$. J. Bacteriol. 177:6585-6.592

43. Liu, S.-L., A. Hessel, H.-Y. M. Cheng, and K. E. Sanderson. 1994. The $X h a \mathrm{I}-B \ln \mathrm{I}-\mathrm{C} e u \mathrm{I}$ genomic cleavage map of Salmonella paratyphi B. J. Bacteriol. 176:1014-1024

44. Liu, S.-L., A. Hessel, and K. E. Sanderson. 1993. Genomic mapping with I-Ceul. an intron encoded endonuclease specific for genes for ribosomal RNA. in Salmonella spp.. Escherichia coli, and other bacteria. Proc. Natl. Acad. Sci. USA 90:6874-6878.

45. Liu, S.-L., A. Hessel, and K. E. Sanderson. 1993. The $X b a I-B \ln 1-C e u$ genomic clcavage map of Salmonella enteridis shows an inversion relative to Salmonella tophimurium LT2. Mol. Microbiol. 10:655-664

46. Liu, S.-L., and E. Sanderson. 1995. Rearrangements in the genome of the bacterium Salmonella typhi. Proc. Natl. Acad. Sci. USA 92:1018-1022.

47. Liu, S.-L., and K. E. Sanderson. 1995. Genomic cleavage map of Salmonella typhi Ty2. J. Bacteriol. 177:5099-5107.

48. Liu, S.-L., and K. E. Sanderson. 1995. I-CeuI reveals conservation of the genome of independent strains of Salmonella tophimurium. J. Bacteriol. 177: $3355-3357$.
49. López-García, P., A. St. Jean, R. Amils, and R. L. Charlebois. 1995. Genomic stability in the archaeae Haloferax volcanii and Haloferax mediterranei. J. Bacteriol. 177:1405-1408.

50. Lorenz, M. G., and W. Wackernagel. 1994. Bacterial gene transfer by natural genetic transformation in the environment. Microbiol. Rev. 58:563-60)2.

51. Ludwig, W., G. Kirchhof, N. Klugbauer, M. Weizenegger, D. Betzl, M. Ehrmann, C. Hertel, S. Jilg, R. Tatzel, H. Zitzelsberger, S. Liebl, M. Hochberger, J. Shah, D. Lane, P. R. Wallnöfer, and K. H. Scheifer. 1992. Complete $23 \mathrm{~S}$ ribosomal RNA sequences of Gram-positive bacteria with a low DNA G+C content. Syst. Appl. Microbiol. 15:487-501.

52. Mahan, M. J., A. M. Segall, and J. R. Roth. 1990. Recombination events that rearrange the chromosome: barriers to inversion, p. 341-349. In K. Drlica and M. Riley (ed.). The bacterial chromosome. American Society for Microbiology. Washington. D.C.

53. Marshall, P., and C. Lemieux. 1992. I-CeuI endonuclease recognizes a sequence of 19 base pairs and preferentially cleaves the coding strand of the Chlanvdomonas moewasii chloroplast large subunit rRNA gene. Nucleic Acids Res. 20:6401-6407.

54. Morgan, A. F., and H. F. Dean. 1985. Chromosome map of Pseudomonas putida PPN. and a comparison of gene order with the Pseudomonas aeruginosa PAO chromosome map. J. Gen. Microbiol. 131:885-896.

55. Obradors, N., and J. Aguilar. 1991. Efficient biodegradation of high-molec ular-weight polvethylene glycols by pure cultures of Pseudomonas stutzert. Appl. Environ. Microbiol. 57:2383-2388.

56. Ojaimi, C., B. E. Davidson, I. Saint Girons, and I. G. Old, 1994. Conservation of gene arrangement and an unusual organization of rRNA genes in the linear chromosomes of the Lyme disease spirochaetes Borrelia burgdorferi, $B$. garinii and B. afzelii. Microhiology 140:2931-2940.

57. Palleroni, N. J. 1993. Structure of the bacterial genome, p. 57-98. In M Goodfellow and A. G. O'Donnell (ed.), Handbook of new bacterial svstematics. Academic Press. L.td., London, United Kingdom.

58. Perkins, J. D., J. D. Heath, B. R. Sharma, and G. M. Weinstock. 1993. Xba and $B h 1$ lgenomic cleavage maps of Escherichia coli K-12 strain MG1655 and comparative analysis of other strains. J. Mol. Biol. 232:419-445.

59. Pyle, L. E., T. Taylor, and L. R. Finch. 1990. Genomic maps of some strains within the Mycoplasma mycoides cluster. J. Bacteriol. 172:7265-7268.

60. Rainey, P. B., and M. J. Bailey. 1996. Physical and genetic map of the Pseudomonas fluorescens SBW25 chromosome. Mol. Microbiol 19:521-533.

61. Rainey, P. B., I. P. Thompson, and N. J. Palleroni. 1994. Genome and fatty acid analysis of Pseudomonas stutzeri. Int. J. Syst. Bactcriol. 44:54-61.

62. Riley, M., and K. E. Sanderson. 1990). Comparative genetics of Escherichia coli and Salmonella typhimurium. p. 85-95. In K. Drlica and M. Riley (ed.) The bacterial chromosome. American Society for Microbiology, Washing ton. D.C.

63. Rodley, P. D., U. Römling, and B. Tümmler. 1995. A physical genome map of the Burkholderia cepacia type strain. Mol. Microbiol. 17:57--67.

64. Römling, U., J. Greipel, and B. Tümmler. 1995. Gradient of genomic diversity in the Pseudomonas aenuginosa chromosome. Mol. Microbiol. 17:323332

65. Römling, U., D. Grothues, W. Bautsch, and B. Tümmler. 1989. A physica genome map of Pseudomonas aeruginosa PAO. EMBO J. 8:4081-4089.

66. Römling, U., D. Grothues, T. Heuer, and B. Tümmler. 1992. Physical genome analysis of bacteria. Electrophoresis 13:626-631.

67. Römling, U., T. Heuer, and B. Tümmler. 1994. Bacterial genome analysis by pulsed ficld gel electrophoresis techniques, p. 355-406. In A. Chrambach. M. J. Dunn. and B. J. Rafola (ed.). Advances in electrophoresis. VCH Weinheim, Germany.

68. Rosselló, R., E. García-Valdés, J. Lalucat, and J. Ursing. 1991. Genotypic and phenotypic diversity of Pseudomonas stutzeri. Syst. Appl. Microbiol. 14: $150-157$.

69. Rosselló, R., E. García-Valdés, A. J. L. Macario, J. Lalucat, and E. Conway de Macario. 1992. Antigenic diversity of Pseudomonas stutzeri. Syst. Appl. Microbiol. 15:617-623.

70. Rosselló-Mora, R. A.. J. Lalucat, and E. R. B. Moore. Syst. Appl. Microbiol. in press.

71. Rosselló-Mora, R. A., E. García-Valdés, and J. Lalucat. 1993. Taxonomic relationship between Pseudomonas perfectomarina and Pseudomonas stutzeri. Int. J. Syst. Bacteriol. 43:852-854.

72. Rosselló-Mora, R. A., J. Lalucat, W. Dott, and P. Kämpfer. 1994. Biochemical and chemotaxonomic characterization of Pseudomonas stutzeri genomovars. J. Appl. Bacteriol. 76:226-233.

73. Rosselló-Mora, R. A., J. Lalucat, and E. García-Valdés. 1994. Comparative biochemical and genetic analysis of naphthalene degradation among Pseudomonas stutzeri strains. Appl. Environ. Microbiol. 60:966-972.

74. Sambrook. J., E. F. Fritsch, and T. Maniatis. 1989. Molecular cloning: a laboratory manual, 2nd ed. Cold Spring Harbor Laboratory Press, Cold Spring Harbor, N.Y.

75. Schmidt, K. D., B. Tümmler, and U. Römling. 1996. Comparative genome mapping of Pseudomonas aeruginosa PAO with $P$. aenuginosa $\mathrm{C}$, which be longs to a major clone in cystic fibrosis paticnts and aquatic habitats. J Bacteriol. 178:85-93.

76. Sinclair, M. I., and B. W. Holloway. 1991. Chromosomal insertion of TOI 
transposons in Pseudomonas aeruginosa PAO. J. Gen. Microbiol. 137:11111120.

77. Southern, E. M., R. Anand, W. R. A. Brown, and D. S. Fletcher. 1987. A model of separation of large DNA molecules by crossed field gel electrophoresis. Nucleic Acids Res. 15:5925-5943.

77a.Stanier, R. Y., N. J. Palleroni, and M. Doudoroff. 1966. The aerobic pseudomonads: a taxonomic study. J. Gen. Microbiol. 43:159-271.

78. Taylor, D. E., M. Eaton, W. Yan, and N. Chang. 1992. Genome maps of Campylobacter jejuni and Campylobacter coli. J. Bacteriol. 174:2332-2337.

79. Thuring, R. W., J. B. Sanders, and P. A. Borst. 1975. Freeze-squeeze method for recovering long DNA from agarose gels. Anal. Biochem. 66:213-220.

80. Toda, T., and M. Itaya. 1995. I-CeuI recognition sites in the $m$ operons of the Bacillus subtilis 168 chromosome: inherent landmarks for genome analysis. Microbiology 141:1937-1945.
81. Ursing, J. B., R. A. Rosselló-Mora, E. García-Valdés, and J. Lalucat. 1995. Taxonomic note: a pragmatic approach to the nomenclature of phenotypically similar genomic groups. Int. J. Syst. Bacteriol. 45:604.

82. Yee, T. W., and D. W. Smith. 1990. Pseudomonas chromosomal replication origins: a bacterial class distinct from Escherichia coli-type origins. Proc. Natl. Acad. Sci. USA 87:1278-1282.

83. Zuerner, R. L., J. L. Hermann, and I. Saint Girons. 1993. Comparison of genetic maps for two Leptospira interrogans serovars provides evidence for two chromosomes and intraspecies heterogeneity. J. Bacteriol. 175:54455451.

84. Zumft, W. G. 1992. The denitrifying prokaryotes, p. 554-582. In A. Balows, H. G. Trüper, M. Dworkin, W. Harder, and K.-H. Schleifer (ed.), The prokaryotes. Springer-Verlag, Berlin, Germany. 